\title{
Systems in Geography or Geography of Systems? Attempts to Represent Spatial Distributions of Australian Social Organisation
}

\section{Laurent Dousset}

Cartography, we now being to realize, is the product of wider discourses, a form of power-knowledge caught up with the major transformations of world history, created and received by human agents, exploited by elites, to materialize as a world seen through a veil of ideology. (Harley 1991, p. 16)

It is now generally accepted that maps are social constructions rather than depictions of an objective reality, and insights from recent studies have enlarged and deepened our understanding of cartography. (Etherington 2007, p. 1)

Maps are undoubtedly complex objects that tend to create lives of their own, and in this respect, Australia has always been one of the most fascinating regions. The futurist European maps of the sixteenth and seventeenth centuries depicted a Terra Incognita or Terra Australis (see Figure 1) yet to be 'discovered'. The utopian literature that accompanied the phantasms of a yet-to-be-revealed extraordinary land complemented these maps (e.g. de Foigny 1676). Australia was a reality before it was discovered, not only because of its Indigenous inhabitants but also as an idea in Europe that started with Pythagoras five centuries BCE. It continued to occupy the European mind with Marco Polo's tales and 
the rich land called Lucac ${ }^{1}$ (see Figure 2) that was then thought to be the 'undiscovered' continent, as well as the speculation regarding the location of the biblical Ophir mentioned in the Books of Kings and the Books of Chronicles, from which the gold for the construction of King Solomon's temple was brought in. The representations of Terra Australis and the maps that depicted the imaginary continent ended up becoming part of the motives for the many expeditions to the Pacific (see Estensen 1998). The graphical representation of Terra Australis in maps as an economically and culturally rich sister of the old European continent became a proof of its existence and an engine for one of the most important changes in human history: the colonisation of the Pacific.

Whatever they represent, maps tend to legitimate and establish the foundations of a particular vision of reality-whether it be observed, reconstructed or entirely imagined. Conversely, once drawn, maps also embody the power to describe things without the need for actual seeing and so become, according to Latour (1987), autonomous actors in the transmission and translation of knowledge. As independent objects, maps end up engendering and replicating a truth that is disconnected from the context and understanding or imagination at their origin. Their capacity to speak through symbols alone, without text and voice, as well as their transportability, limited physical extent and easy reintegration into new frameworks of knowledge production and transmission are likely responsible for their popularity and the fascination they generate.

Through these characteristics, maps stand as objects of authority and power, providing overviews and a vertical perspective, summarising and necessarily stereotyping facts into a single and simplified world (D'Andrade 1992). By revealing some aspects and omitting others, they offer a sense of dominance and an appreciation of the capacity to grasp a sphere that is otherwise too complex and diverse to assimilate. Maps define points and areas; draw boundaries and borders; stress distinctions and similarities, difference and sameness, continuities and discontinuities (or discontinuities through continuities); and create 'land' through the portrayal of a virtual space through the use of criteria that necessarily tend towards generalisation and representativeness. They construct history through selecting certain traces, while consigning others to oblivion (Ricoeur 2000).

1 Also spelled 'Locach' or called 'La Joncade' by Le Testu (1556; see also Lestringant 2013). 


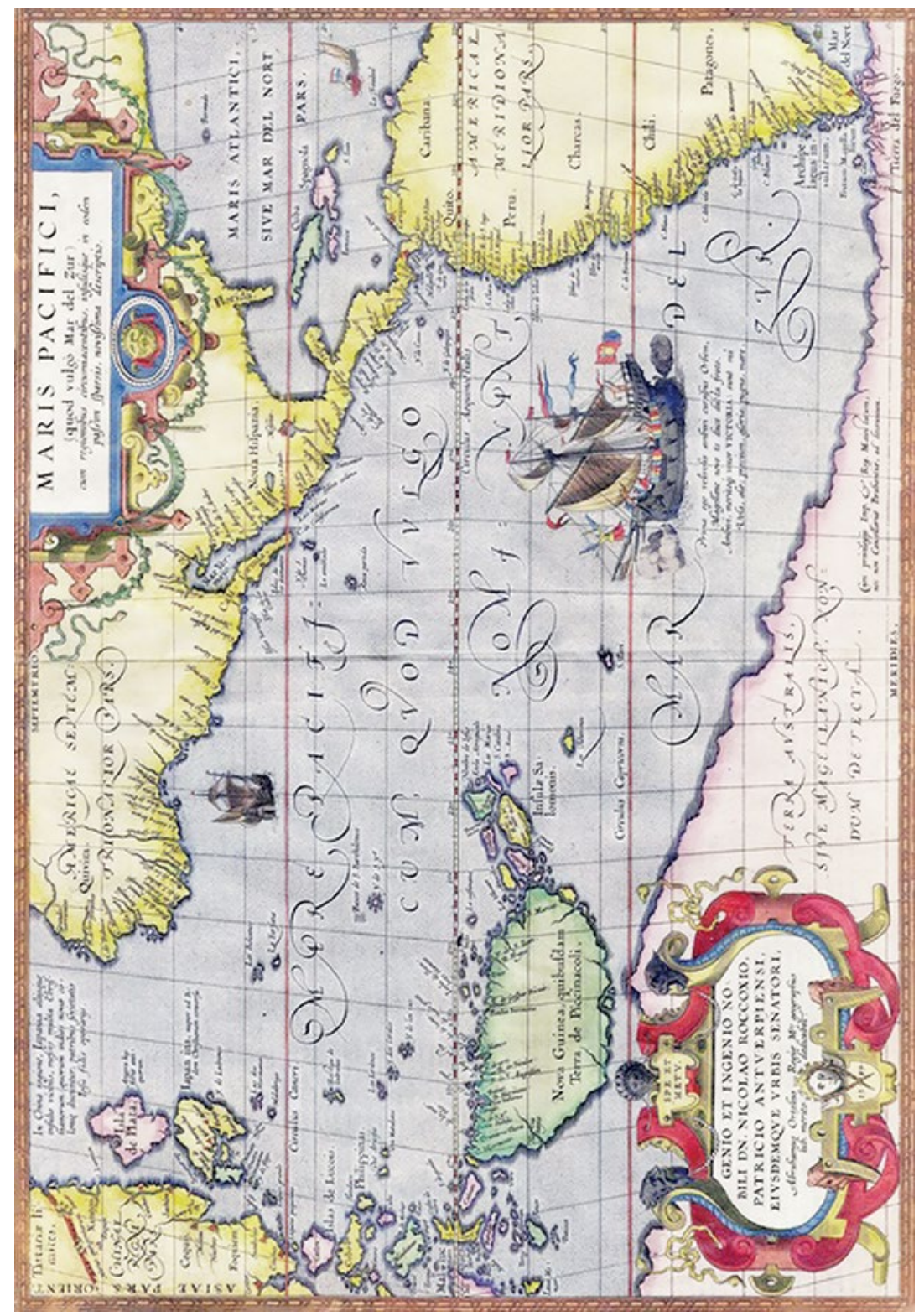

Figure 1: Maris Pacifici showing Terra Australis by Abraham Ortelius (33 x 48 cm; scale: 1:40,000,000), Anvers: Imprimerie Plantinienne, 1589. Source: Wikipedia (2012). 


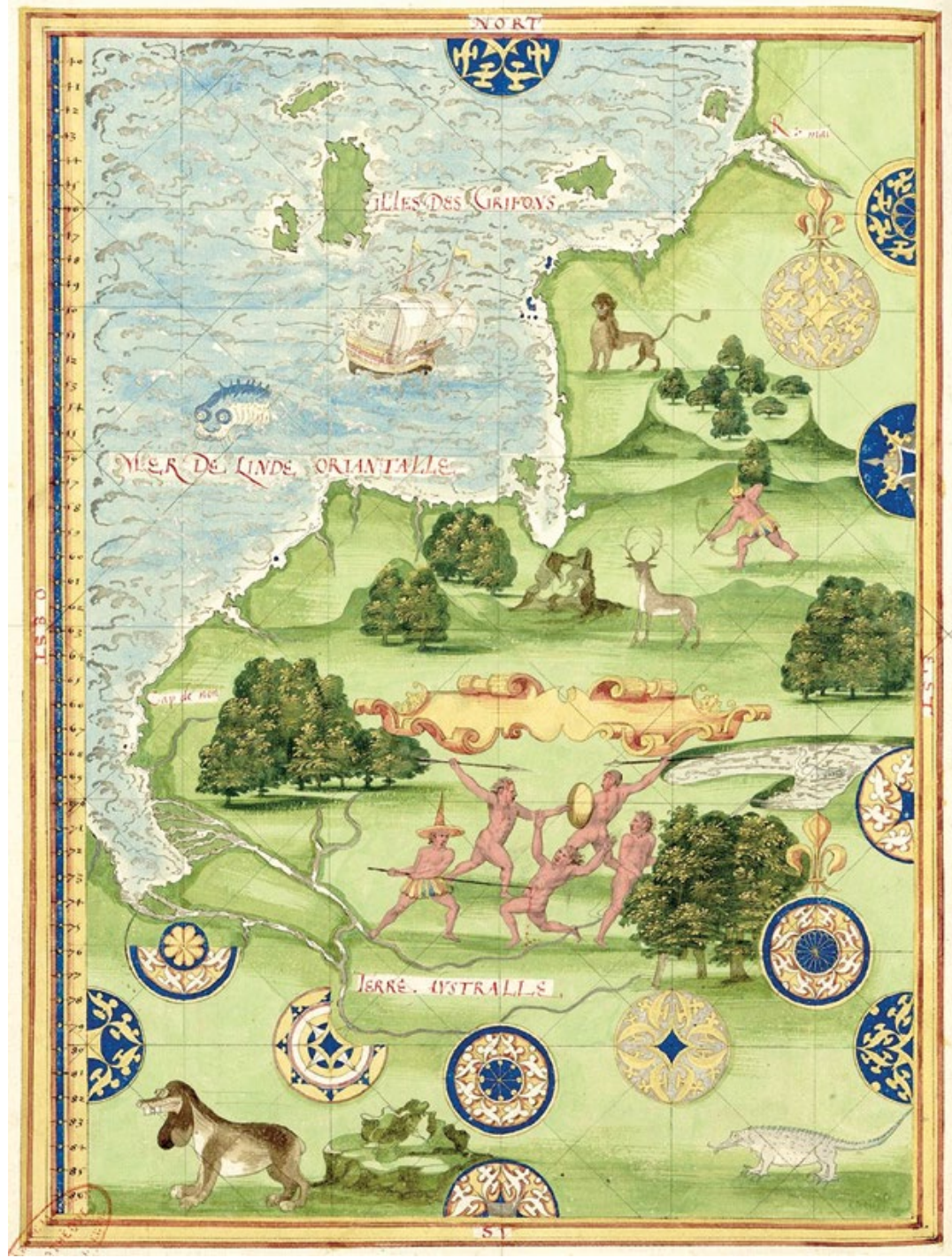

Figure 2: Cette terre est dite la région Australe (This land that is called the Australian region) by Guillaume Le Testu, FO XXXV, Le Havre, 1556. Source: Le Testu (1556). 
What has been sketchily summarised regarding the power of maps in general, and maps of Australia in particular, is also valid in the realm of the specific geographic representations developed to draw Indigenous Australian cultures. ${ }^{2}$ However, it is also due to this inherent power of maps that:

Mapping indigenous people across the whole continent of Australia has been riddled with difficulties ... The three maps that have set out to do this for the whole of Australia in the late 20th century-by Norman Tindale [1974], Stephen Davis [1993], and David Horton [1996] maps-have been contentious. (Blackburn 2002, p. 134)

These attempts involve an 'Aboriginal territoriality according to nonAboriginal concepts of boundaries' that is 'fraught with danger' (cf. Sutton 1995; Young 1995). However, it seems that the awareness of the contentious nature of mapping Australian Indigenous cultures is not limited to recent writings. Blackburn did not consider Davidson's (1938) 'ethnic map of Australia', since it is earlier than the period considered by Blackburn in the late twentieth century. Interestingly, Davidson was cautious enough not to draw boundaries around his 'tribes', and simply placed names in a rather geographically neutral space. Was it because Davidson could not do so, or because he did not want to consider territoriality? Was he aware of the inherent difficulties that lines and areas drawn on a map would produce in a colonial context? Or had the intellectual and political environments changed during the second half of the twentieth century, driving researchers such as Tindale (1974) and Horton (1996) to create those maps that Blackburn qualified as contentious?

This chapter attempts to elaborate on the background to these questions, and succinctly articulate the evolution of a style of mapping in which it was Aboriginal social organisation that very early on became the means through which cultural distinctions or similarities, and different historicities more generally, were represented and defined in space. Further, the chapter attempts to place these mapping styles against their general scientific background. I use the expression 'social organisation' as it was shaped and used by Howitt and Fison (1885), meaning a systematic division of a group into a usually even number of categories - such as moieties, sections or subsections-on which marriage regulations are based. Interestingly, in the context of mapping, Howitt (1996 [1904],

2 This chapter will not deal with Indigenous modes of representing space. The reader may want to consult Sutton's (1998a, 1998b) two chapters in this realm. 
pp. 42-3) distinguished 'social organisation' from what he called 'local organisation', with the latter including geographical groupings called 'clans' in which there is patrilineal descent and 'hordes' in which there is matrilineal descent-which one would think more prone to being mapped.

In some mapping styles, the distinction between social and local organisation was not as clear-cut as Howitt had expressed, which meant that these two domains were sometimes blurred. Moreover, kinship and social organisation in particular were not the only domains of Indigenous society to be mapped. Material culture or ritual characteristics, such as bodily markings during initiations and linguistic classifications, have been frequently represented in space (see Davidson 1936; Mathews 1900; Schmidt 1912) with the aim of reproducing a geographical space reflecting cultural affinities and differences. Of course, 'tribal' distribution has been another object of mapping (see Connelly 1932; Davidson 1936; Mathews 1900; Schmidt 1912). What is particularly interesting about mapping social organisation is that it has been interpreted as a domain that crystallises and typifies Indigenous diversity and similarity, as well as evolution: an opportunity to map time and space simultaneously. Social organisation has often been understood as a marker for change or governance, ${ }^{3}$ and as such it has been used to reveal an internal social structure in such a way that it becomes efficient for large-scale comparison-be it within or beyond the Australian scope. In one way or another, maps exposing other cultural characteristics had to reflect or at least overlap to some extent with the distribution of social organisation.

After a brief introduction to Australian social organisation, the chapter suggests three main historical periods - the homogenisation period, the organic period and the dynamic period—in which Australian Indigenous people have been conceptualised within their own homogeneity and diversity through the device of mapping. These periods are not necessarily clearly distinguished from each other and overlap to some extent, essentially operating as a rhetoric device and allowing the typification of certain principles (and scientific ideologies) and characterisation of what I believe to be the evolution of anthropological mapping.

3 I do not limit the notion of governance to the question of authority and its legitimisation, but extend it to embrace all that can be considered in shaping the public space, such as obligations of redistribution and rights of access to material and immaterial resources, rules of marriage and circulation of people, as well as systems of land tenure and ritual activity. 
For each period, I only mention a few important authors, mostly anthropologists, ${ }^{4}$ with no attempt to be exhaustive, but with the aim of discussing the main features and authoritative messages that their maps convey. Maps not only represent 'systems' in space and systems in geography alone, but are also a means to legitimate and illustrate particular epistemologies and their evolution: they become geography or even geometry of systems.

\section{What is Social Organisation?}

When anthropologists use the concept of 'social organisation' with respect to Australia in particular, they are not implying a vague idea about the administration of social life in general, but understanding — since Howitt and Fison's (1885) contribution at least-the linguistic and sociological features that are considered specific to, and certainly widespread if not universal in, Aboriginal languages and cultures. The notion of social organisation in Australia reflects linguistic, conceptual and classificatory devices that distribute all members of a group and beyond-and also mythical figures in many languages - into an even number of categories that stand on top of or alongside kinship terminologies or systems of land tenure, and that are interrelated in particular and sometimes complex ways (for an overview and discussion, see Dousset 2011). Australian social organisation has garnered considerable attention, if not fascination, from numerous scholars. To quote one example, Lévi-Strauss (1996 [1973], pp. 41-2) admired the 'crystalline beauty' of the systems that Australian cultures had developed.

There are different types of classificatory devices, and I will summarise the most representative systems without going into too much formal detail. Some of the features of these systems have been used in the AustKin project (see Figure 3) to record and process data, as well as map social categories.

4 I do not and cannot deal with archaeology, linguistics, political sciences, demography and, of course, geography itself in this chapter. However, I would suggest that while archaeology and linguistics have to some extent developed their own (although in correspondence with anthropology) means of mapping Australian Indigenous cultures, the other disciplines rely heavily on anthropological mapping. 
Systems of social organisation can be divided into two general types. The first type is dualistic in that it opposes two social categories that stand in a direct and identical relationship to each other. The second type could be called indirect dualistic; it still articulates an even number of categories, but these categories do not all stand in an identical relationship to each other. Dualistic systems are moiety systems of which there are two subtypes: matrimoieties and patrimoieties. In these systems, the categories stand in a marriage relationship to each other. Merged alternate generational levels-also called generational moieties-are another system that is of the dualistic type. These are organised around a relationship of filiation, rather than marriage. In particular, patrimoiety and matrimoiety systems are well spread throughout the world and are found in many languages.

Indirect dualistic systems are section, subsection and semi-moiety systems. They are rare on a world scale and generally considered limited to Australia, although some kind of section system seems to be used by groups among Panoan speakers in South America (see Chapter 8; Fleck 2013 cited in McConvell 2013; Hornborg 1993; McConvell 2013). Section or similar systems have also been reported to have existed in ancient China (Cooper 1983; Kryukov 2004) and are in use on the island of Ambrym in Vanuatu (Lane \& Lane 1956; Patterson 1976), although the structure of these systems is different from the one found in Australia.

Dualistic systems divide society into two halves that stand in a direct and unique type of relationship to each other. In matrimoiety systems, a person belongs to the same moiety as his or her mother and marries a person of the other moiety, where his or her father came from. In a patrimoiety system, a person belongs to the same moiety as his or her father and marries a person of the other moiety, where his or her mother came from.

Generational moieties are different from the two former systems, as they are not organised by marriage relationships and instead express a relationship of filiation. In this system, a person sits in the same moiety as his or her brothers, sisters and cousins, and grandparents and grandchildren. The other moiety includes a person's fathers and mothers, aunts and uncles, children, nephews and nieces. The relationship between these two moieties is one of filiation (parent-child; child-parent) and not intermarriage, as is the case for the two other moiety systems. 


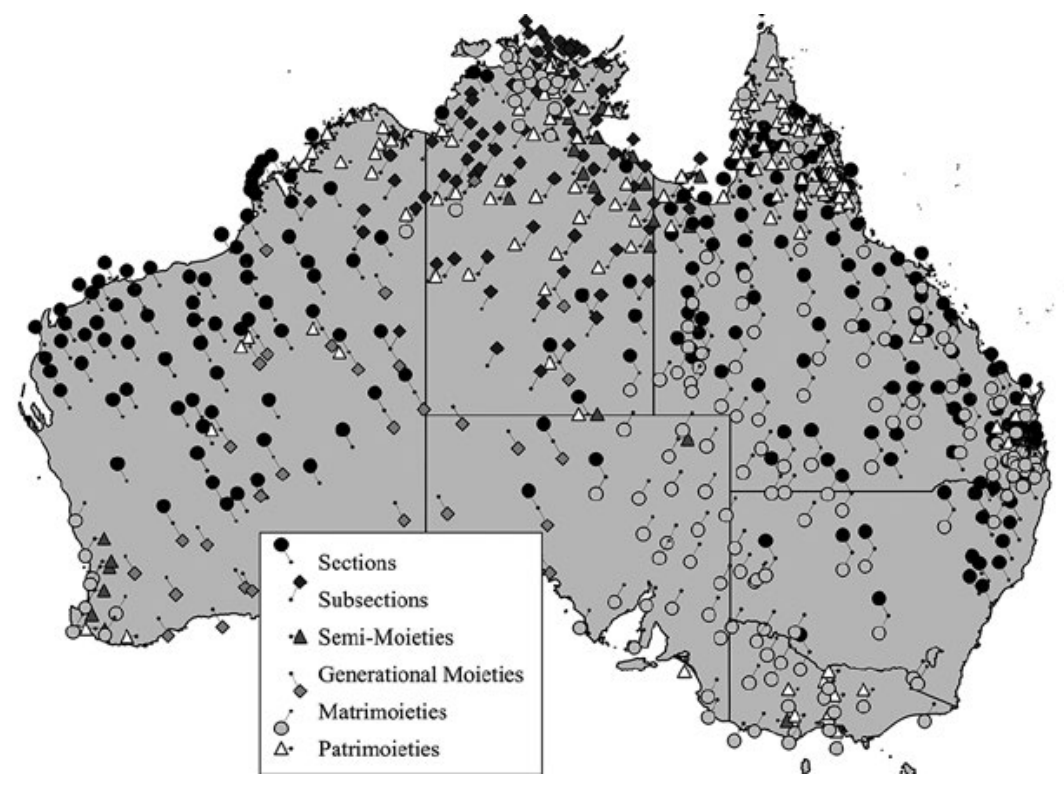

Figure 3: The distribution of some system types in Australia following the AustKin database.

The database has information on 273 sections, 105 subsections, 23 semi-moieties, 154 matrimoieties, 114 patrimoieties and 38 generational moieties. The approximate locations of the languages that know such systems are represented in the map: 172 with sections, 59 with subsections, 17 with semi-moieties, 120 with matrimoieties, 86 with patrimoieties and 29 with generational moieties. A total of 348 languages or dialects, past or present, are documented. One language may use more than one system type. Note that this map does not take into account historical changes or the diffusion of system types, but is a general snapshot of all systems that at any known time in history were or are used by a language.

Source: Author's map built through the AustKin interface, using NaturalEarthData.com open source contour data on QGIS.

Conversely, indirect dualistic systems divide society into more than two categories that stand in various types of relationships to each other, such as marriage, father-child and mother-child. Subsection and semimoiety systems divide society into eight categories. Some subsection terminologies additionally account for gender differences. Section systems divide society generally into four categories (and some have an additional gender difference).

Three more elements are important to note before we move on to consider the evolution of the mapping of these systems. First, in most, if not all, languages, social categories not only include and classify human beings but also mythological figures or natural species that each sit in one of the available classes. Second, it is well known that social category systems- 
sections and subsections, in particular-spread over vast areas of Australia before colonisation (see Dousset 2005; McConvell 1985a, 1996). They are particularly convenient in intertribal and interlanguage encounters and are therefore prone to diffusion because they appear as a simplification, work as a ready-reference index (Fry 1933) and even constitute a lingua franca of kinship. A map displaying the distribution of these systems may thus reveal significant changes from the same map drawn 50 years earlier. Third, social categories have specific Indigenous labels-the moiety names, section names or subsection names themselves-as the examples in Figure 4 illustrate. Therefore, two characteristics have become the object of mapping: the system types themselves and also the Indigenous names that denote the categories within the system.
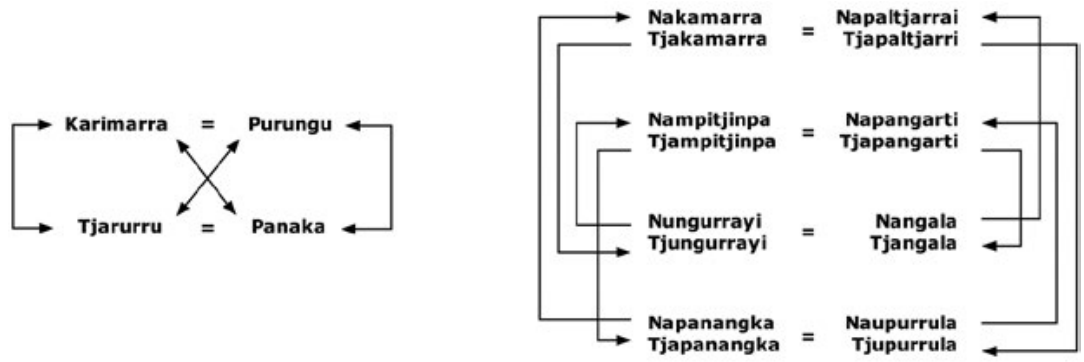

Figure 4: Example of a section system (left) of the Ngaatjatjarra group and of a subsection system (right) of the Warlpiri language.

Equal signs link intermarrying (sub)sections; vertical arrows indicate mother-child relationships; diagonal lines in the section system indicate father-child relationships. For examples of semi-moiety systems, see Maddock (1972); Shapiro (1969).

Source: Author's work.

The Indigenous names given to these categories are usually absolute. This means that the name of the category in which a person stands does not change depending on the speaker. A notable exception is the generational moiety, in which there may be relative and absolute names. This is the case for the Western Desert Ngaatjatjarra people who know both relative and absolute terminologies. The absolute names of these moieties are Tjintultukultul (meaning sun-side) and Ngumpaluru (meaning shadeside). A person is born into one of these two categories. Conversely, the relative names are Nganatarka (meaning 'us, we bone') and Tjanamilytjan (meaning 'them, they flesh') (see Goddard 1992 [1987]). Every person says he or she sits in the Nganatarka moiety, while people from the other moiety are said to stand in the Tjanamilytjan moiety. 


\section{Homogenisation: Early Mapping of Aboriginal 'Evolution'}

Many of the early attempts to map Australian Indigenous 'nations' or 'tribes' were already based on displaying similarities and distinctions in the domain of social organisation. For example, Mathews's 1900 map (see Figure 5) attempts to group tribes and groups following two criteria: initiation ceremonies that he saw to function as a means of regional and mutual integration and, more importantly, shared 'divisions' (moiety, section and subsection systems and names) (see Blackburn 2002, p. 147).

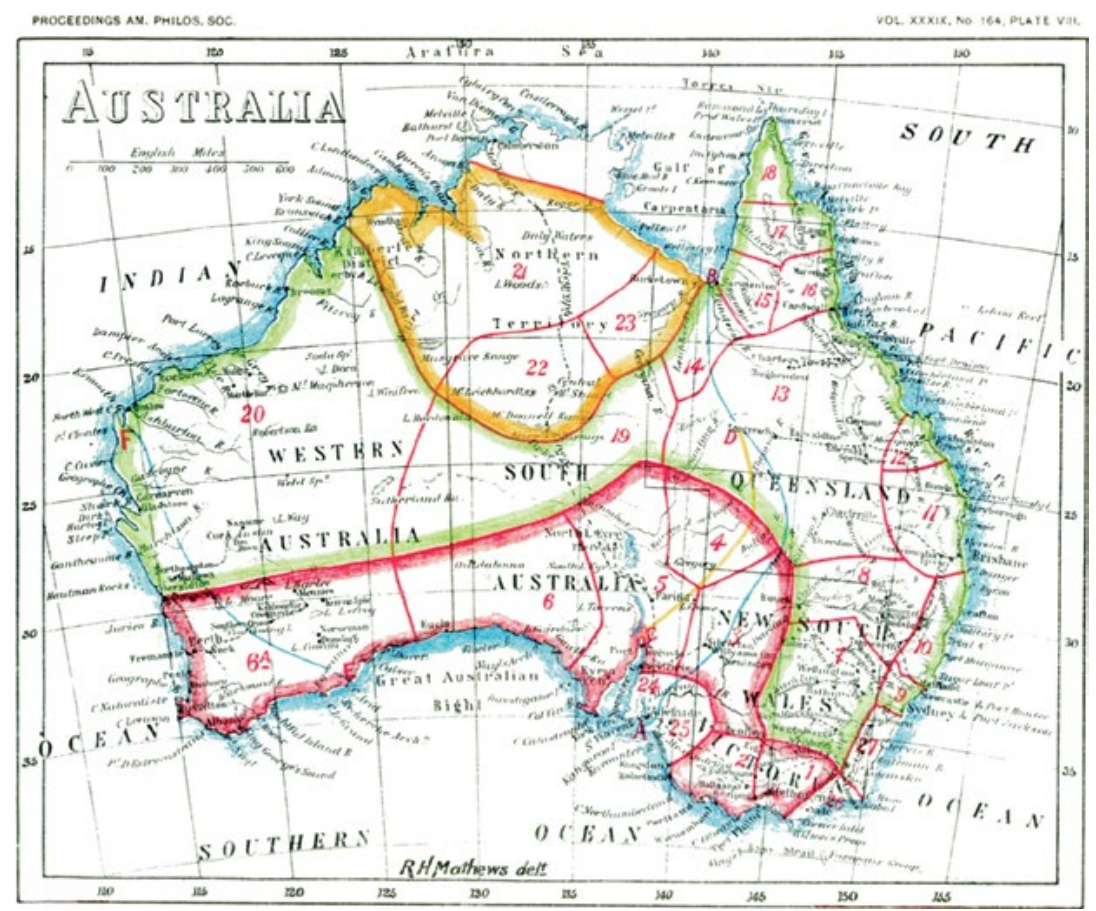

Figure 5: Mathews's Aboriginal nations according to similar or identical moiety, section or subsection names (thin lines and numbered areas) and identical system types (shaded lines and large areas).

Source: Mathews (1900). 
The following quotations are extracts from Mathews's own explanations of his map:

A tribe is divided into sections, which are known by distinguished titles ... The names of these divisions vary in different districts. In a certain tract of country the sections will be known by one set of names, whilst among adjoining tribes a different nomenclature will be employed. Aggregates of tribes holding the same divisional names may, for convenience of reference, be called communities or nations [the thin lines and numbered areas in the map].

I have prepared a map, showing New South Wales, Queensland, Victoria, South Australia and Western Australia, on which is shown the position of the boundaries of the several nations, each of which is distinguished by a numeral, from 1 to 27. In explaining this map I shall commence with the several nations possessing two divisions [moieties], then those with four divisions [sections], next the tribes with eight divisions [subsections], and lastly a brief reference will be made to those tribes whose marriage laws are of the tooar type [mother-in-law bestowal; areas 24 to 27 in the map]. (Mathews 1900, pp. 574-5).

The shaded lines in the map, dividing Australia into three ${ }^{5}$ large areas, represent the grouping of similar system types (as opposed to the fine lines inside these larger areas that represent the grouping of system types and the linguistic proximity of the division names). The southern area reflects the distribution of two division systems (moieties; red in the original colour map); the central area, reaching up to north Queensland in the east, depicts the distribution of the four-division system (sections; green); and the north-central area (numbers 21, 22 and 23) is characteristic of eight divisions (subsections; yellow-orange). Later, we will see that Mathews was not that far off in his representation, and, provided some tolerance is accorded, current anthropologists and linguists accept his general picture (see Figure 8). The strict boundaries that he drew between moiety, section and subsections areas - separated by harsh and thick lines-are significant, and each integrate several 'nations' that themselves are built around the resemblances of the names of these items of social organisation. Moreover, the three types of social organisation systems that function here as the witness of veritable cultural and social boundaries never overlap or crisscross. Instead, they constitute three neatly defined and distinguished geographic areas - and, as we will see, historical layers. Here, the types of

5 In fact, there are four areas within the Top End, for which he does not provide any information or classification. 
social organisation systems reveal entirely different cultural and historical objects from their ostensible sole purpose of subdividing society into an even number of categories.

Indeed, it is necessary to recall Mathews's ambition in this paper: 'to give a short outline of the probable origin of the native tribes of Australia' (1900, p. 556). He believed that the continent was populated by two waves of migration. The first and most 'primitive' wave is still visible in the south-east, characterised by the existence of the mother-in-law bestowal. 'In some respects', he wrote, 'these people differ in physical type, in weapons, in language and in their ceremonies, from the natives of other parts of Australia, but resemble in several particulars the inhabitants of Tasmania' (1900, p. 560). The second wave of migration is progressive, with tribe after tribe moving into the continent. Mathews believed these migrations and the subsequent competition and warfare among the tribes were the reasons these groups elaborated systems of exchange of women between them in order to settle in new territories and engage in peaceful relationships. Thus, the moiety, section and subsection names all represent the original tribal names of these newly intermarrying groups. The further north we move, the more complex the intertribal alliances become, superimposing themselves onto previously established and simpler intertribal relationships: first between two, then four and finally eight tribes. According to Mathews, the map of social organisation is a map reflecting the history of migration, with more 'modern' tribes progressively imposing themselves onto the sociocultural landscape. The boundaries between systems seem to reflect the geographical reach of waves of new migrations.

Despite the fact that Mathews was a great traveller and had visited many of the Australian regions, as well as read (even though he seldom acknowledged) the existing ethnography, we are faced with a largely evolutionary approach shared by most of his contemporaries: attempts to elaborate maps in which cultural particulars reflect historical chronology, and in which boundaries represent temporal and evolutionary stages. Even though Howitt was a fine ethnographer, scrupulously distinguishing 'facts' from 'theories' (Keen 2000), he had also been tempted by these large-scale and generalising hypotheses, such as when he wrote that the division of the people of the tribe into two classes [moieties] is the foundation from which the whole social organisation of the native tribes of Australia has been developed' (Howitt 1996 [1904], p. 89). ${ }^{6}$

6 See Howitt (1883, p. 496) where he thought 'that the early state of their society was that of an undivided commune'. 
Schmidt $(1912,1919)$ adopted a similar approach to that of Mathews when he attempted to represent the history of migration and social evolution of Australian Aboriginal tribes and languages through mapping. Similar to Mathews, Schmidt believed that the structure and form of social organisation known by groups attest to cultural and historical affinities. However, Schmidt's approach is a linguistic one. His ambition drove him even further than Mathews in attempting to reconstruct the historical linkages between Australian and Asian languages and cultures. Schmidt identified several large groupings_-of which the Tasmanians are the oldest representatives - that reflect waves of migration to the continent. Inspired by Graebner (1906), a geographer and ethnologist who fostered the Kulturkreis theory in Vienna, Schmidt related the age of migration to the complexity of social organisation and placed this within the classification of languages. The older a language and a system, the fewer the social categories used to structure society. Despite the historical approach adopted, Schmidt challenged the evolutionary theory and underlined the importance of migration, diffusion, recombination and transformation. $\mathrm{He}$ is one of the first scholars to strongly suggest that sections (what I call indirect dualistic systems) are the result of the encounter and combination of languages with matrimoieties and patrimoieties, or dualistic systems.

However, from the twentieth century onwards, the drive to conflate geography and history has gradually been replaced by the new approaches of the functionalist and structural-functionalist schools of Great Britain. Speculation about the evolution and relative homogeneity of Australian Aboriginal societies gave way to an emphasis on synchronicity and typology, ending in the complete refusal of 'conjectural history' (RadcliffeBrown 1941).

\section{The Emergence of Integrated Mapping of the Structural-Functionalist Approach}

The maps of the early decades of the twentieth century reflect an important change, as well as an inherent contradiction (or dialectic) and emergent imperative. An explicit will emerged to distance this new anthropology from the earlier speculative depictions in which Australian Indigenous cultures were often represented as a rather homogeneous unity. The emergence of fieldwork as a central aspect of the anthropological discipline, with researchers reporting a wide variety of structures and 
practices, was obviously a main driving factor in this change. The objective was now to represent this newly discovered diversity and complexity of the cultural and social landscape. Davidson's $(1928$, p. 3) introduction to his thesis is revealing in this respect: ${ }^{7}$

At first glance one might expect that no great difficulties should be encountered in an attempt to determine the cultural and physical affinities of people characterized by such a fair homogeneity of race and by such a comparatively simple material culture as are the Australians. This notion is soon dispelled, however, when one realizes that in spite of the great deal of attention which has been given to these questions, we still seem to be but little nearer [to] the ultimate objective realization than we were at the offset.

Davidson (1928, pp. 4-5) believed former homogenisations were erroneous and generalisations still difficult because ethnography was insufficient:

I believe that the time has not yet arrived for an intensive study of Australian culture. Information is still too scarce and that which we have, collected from localities too scattered ... I am convinced that many ... traits in Australia might have been considered ... However, due to the defects in information I have refused to treat them until we have more data at our command. ${ }^{8}$

Conversely, while the need for more ethnographic data and warnings for too-rapid generalisations were expressed, the necessity for typologies became palpable. Indeed, to accommodate the ethnographic diversity in an approach that largely maintained a continental scope, a movement of thought that heavily relied on establishing new homogeneities despite the newly acquired diversity became necessary. Maps that displayed this new diversity-homogeneity dialectic became both central objects of analysis and summaries of general conclusions, and had important impacts for future research.

\footnotetext{
7 While I am not completely convinced Davidson can be considered a structuralist or functionalist, for he is probably closer to the diffusionist approaches, he also values and depicts many features of the functionalist schools: importance of ethnographic data, avoidance of conjectural history, and social institutions seen in embedded and strongly interdependent terms.

8 In another publication, Davidson (1926) argued that it is necessary 'that higher institutional complexities, which are so common and unique in Australia, be reconstructed upon a sounder basis of consideration and less upon theoretical analogies derived from conditions in other regions of the world', clearly distancing himself from the evolutionist and some of the Kulturkreis scholars.
} 
The will to elaborate unifying and comparative perspectives despite the ethnographic diversity probably reached its apotheosis with Elkin, who was a student of Radcliffe-Brown. In his classic The Australian Aborigines (1974 [1938]), Elkin expounded typologies of social organisation that in many respects intermingle aspects of Aboriginal culture that are not easily perceived to belong to the same level of social reality. 'Each tribe is subdivided into two or more social groups on the basis of locality, age, sex and unilateral relationship' (Elkin 1974 [1938], p. 112), he wrote when introducing his typologies: local groups are generally patrilineal, patrilocal and exogamous; age grouping and age grades reflect the distribution of authority and respect with regard to age; generation lines reflect the distinct terms and groupings of succeeding generations (today called alternate generational levels or moieties); sex grouping is the 'biological fact of sex difference [that] divides the Aborigines into two groups which for some purpose are mutually dependent' (p. 116); social totemic clans are groups of people related in one line only, through the father or mother, and are usually members of a local group or subdivision of a tribe; moieties divide tribes into halves that are definite social and ceremonial groupings; and sections, subsections and semi-moieties are divisions of 'some tribes into four or eight social groups with their own rules of marriage and descent' (p. 124).

Age, generation, gender, locality, totem and social categories appear on identical levels and in a unified perspective in which the centralthat is not to say only-criterion is that of grouping, classification and organisation, preparing the way to reunify a diversity of Aboriginal cultures following rather simplistic distinctions.

Alongside this drive to elaborate criteria that allow the unification of diversity, there emerges another imperative tied to the structuralfunctionalist school. Social structure reflects social institutions and their mutual interdependence: things that are social are coherent with each other. Essentially, social organisation is seen as a means of distributing people and access, as well as transmission of land, and land tenure systems are seen as the pragmatic and materialistic counterparts of kinship and social organisation, such as sections and subsections. In his famous 1913 paper, Radcliffe-Brown engaged in this dialectic and the elaboration of this imperative: he relied heavily on mapping as a mode of arguing and perpetuating a particular way of thinking about Aboriginal society, its diversity and unity, as well as the mutual and organic integration of social domains. 
In this founding paper, Radcliffe-Brown (1913) defined the Kariera as a linguistic and territorial group with a distinct name, a tribe (p. 144) divided into 'local groups' (p. 145) ${ }^{9}$ of which membership is 'determined by descent in the male line' (p. 145) and that collectively own the resources of their territory (p. 146). The local group itself is composed of individual families that move independently within the local group territory (p. 147). Members of the local group need to find a spouse in another group: in the camp of the local group would be found only men and unmarried women and children who belonged to the group by birth, the married women all belonging by birth to other groups' (p. 147). In a few pages, RadcliffeBrown constructed an integrated model of social organisation and land tenure that has remained at the centre of many discussions for decadesand is still significant today, in particular in the context of native title (Dousset \& Glaskin 2007; Glaskin \& Dousset 2011)—in which residence and property are largely coextensive and backed by marriage practice ${ }^{10}$ and social organisation. While he thought (in this paper, as well as later papers) this to be a general Australian model, he also established typologies and underlined to a certain extent the existence of diversities based on additional particular marriage rules and what he referred to as 'classes'.

'The Kariera tribe', Radcliffe-Brown (1913, p. 147) wrote, 'is divided into four parts that I shall speak of as classes', which constitute the section system. Not surprisingly-as the relationships between the classes need to be compatible with the local group model and kinship terminologyhe framed the inherent marriage rules not as prescriptions, but as proscriptions: 'this does not imply that a Banaka [one of the sections] man may marry any Burung [another section] woman, but only that he may not marry a woman of any other class' (p. 148). 'The proper person for a man to marry', he later wrote, 'if it be possible, is his own first cousin'; and well before Lévi-Strauss (1967 [1947]), Radcliffe-Brown explained that 'a common custom in this as in most Australian tribes is the exchange of sisters' (p. 156).

9 The usage and definition of the notion of 'local group' predates Radcliffe-Brown (1913), of course. McLennan (1970 [1865]) had already used this concept. Interestingly, while Radcliffe-Brown does not quote former definitions in his paper, Howitt and Fison (1885) and more particularly Howitt (1996 [1904], p. 89) had underlined the distinction between 'clan' (as a sociogeographical division) and 'horde': the former being a residential group in a patrilineal system whereby land-using groups and land-owning or land-holding groups are equivalent, and the latter being a residential group whereby landownership is inherited matrilineally (see Chapter 4).

10 Of course, others have discussed these issues before Radcliffe-Brown. But his 1913 paper had in my view the most profound impact on the way the representations of Australian Indigenous cultures were subsequently modelled. 
Finally, Radcliffe-Brown (1913, p. 159) eagerly mapped the section system onto his local group model in order to elaborate an integrated and organic view of Aboriginal social organisation and structure (see Figure 6):

The whole tribe is divided into two couples of classes, Banaka-Palyeri and Karimaera-Burung. Each local group, however, that is, each of the local subdivisions of the tribe, consists of members of one couple only. Thus one local group consists of men and women of the classes Karimera and Burung, while another consists of Banaka and Palyeri men and women. In the map of the tribe, underneath the numeral denoting each local group, will be found two letters indicating the couple to which the group belongs. B. P. stands for Banaka-Palyeri, and K. B. for Karimera-Burung. It is thus possible to realize at a glance the geographical distribution of the couples. (emphasis added)

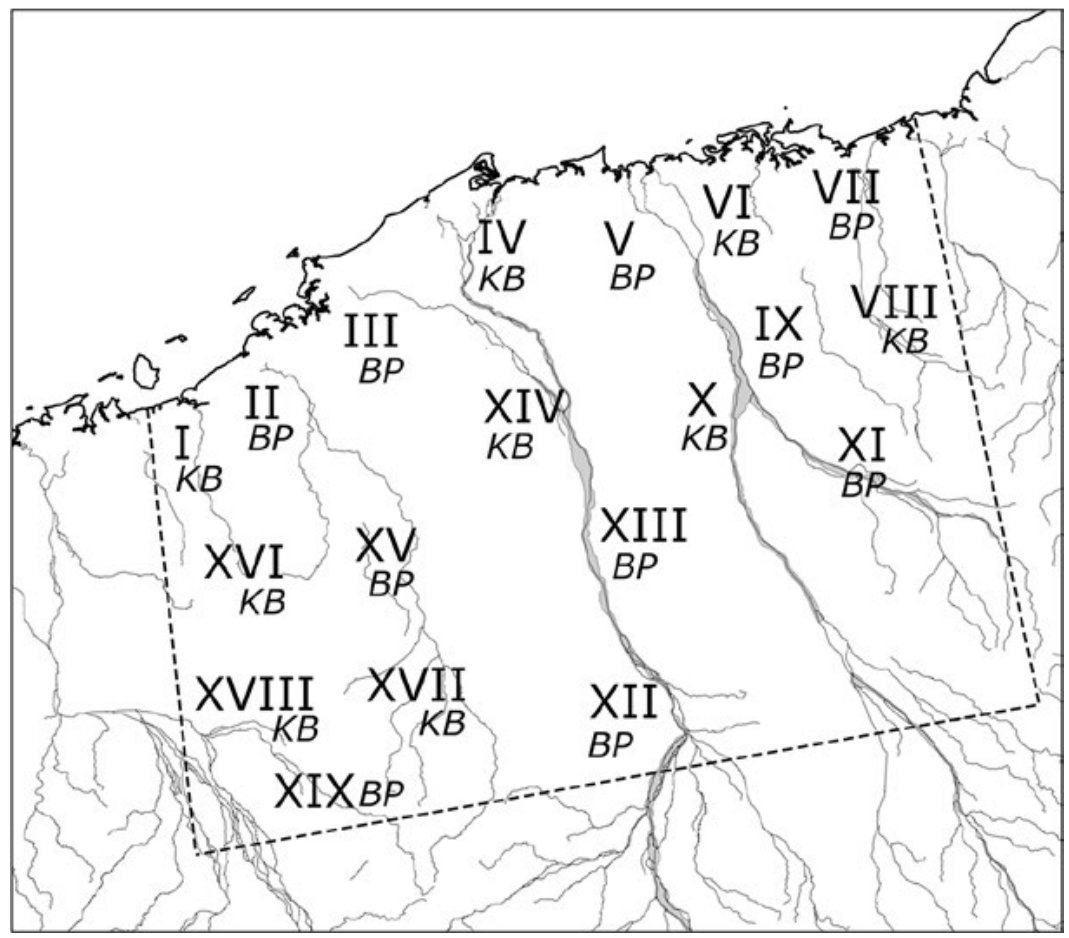

Figure 6: Radcliffe-Brown's vision of the 'Kariera tribe' showing 'local groups' (roman numbers) and associated section couples (letters).

Source: L. Dousset from Radcliffe-Brown's (1913) text and drawing.

Demerath (1966, p. 400) considered Radcliffe-Brown a 'functionalist' in the structural-functionalist school, among those 'guided by an interest in the system as a whole', as opposed to the structuralists of the same school 
that were interested in 'the analysis of a particular part in the system'. Functionalists ran 'the risk of overestimating system unity' and were 'more concerned with internal process than external change' (Demerath 1966, p. 400). In Radcliffe-Brown's obsession to construct an integrated system, an obvious inconsistency in his geographical depiction of social organisation emerged for at least two reasons, as most researchers who have done fieldwork in Aboriginal Australia would immediately recognise. First, all four sections, and not only two, are simultaneously present in any residential group-be it for formal or pragmatic reasons. For example, if we accept patrilineality to be constitutive of local groups, as Radcliffe-Brown wanted it, then one would supposedly find in any local group a male ego (one section) and his wife (a second section), but also that man's father (a third section) and the latter's wife, ego's mother (a fourth section). However, had RadcliffeBrown been consistent with his own patrilineal local group model, then he should have depicted father-son section couples and not spouse couples. It could well be that he chose to model the spouse couple in order to comply with his other assertion about sister-exchange, and in order to stress the mutual interdependence of the many local groups through marriage and the circulation of women. Otherwise, his whole concept of the 'Kariera tribe' would have been highly questionable, or at least unstable since it could not reproduce itself with the same distinctions over time. Whatever the reasons, he made certain choices that resulted in the Kariera tribe-or really the Kariera model—becoming one of the ideal types and underlying configuration of any kind of Australian social organisation. In fact, all other 'types' or 'systems' are depicted as derivations or relatives of this basic theme, initiated on an organic integration of social organisation with land tenure and marriage. Mapping these 'types' and 'systems' truly became a system of mapping rather than a mapping of systems.

\section{The Organic Period: From Mapping a Model to Mapping Typologies}

Due to this integrated understanding of social structure and institutions, mapping social category systems became a means to both map diversity and homogeneity of Aboriginal culture more generally, provided some explicit (or implicit) typology to group Indigenous tribes into regional and panregional subsets (so-called cultural blocks) was articulated. Davidson's (1926, 1928) and Radcliffe-Brown's (1930) maps, differing only a little from each other, are particularly revealing in this respect (see Figure 7). 


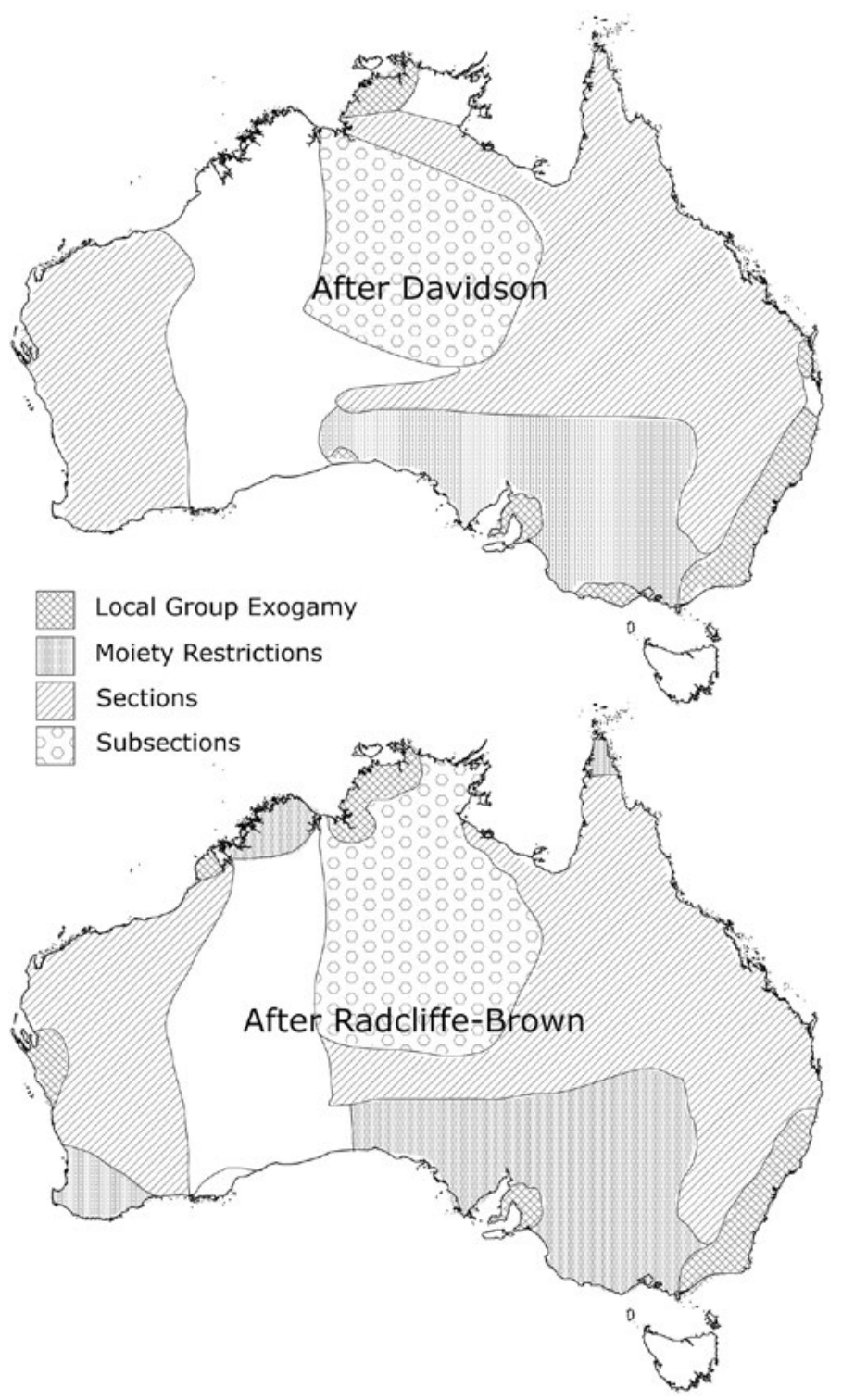

Figure 7: Davidson's and Radcliffe-Brown's maps of the distribution of social organisation in Aboriginal Australia as summarised by Yengoyan. Source: L. Dousset after Yengoyan (1968b, p. 193). ${ }^{11}$

11 It is interesting (and revealing) to note that what Yengoyan labels 'local group exogamy' in his reinterpretation of Davidson's map, Davidson (1926, p. 535) himself simply notes as 'tribes without a class organisation'. 
Not surprisingly, these maps display local group exogamy and social category systems. Even though Radcliffe-Brown repeatedly warned against understanding section and subsection systems as regulating marriage, he is in fact unable to distance himself from this view in which social organisation, marriage and land tenure are intrinsically linked, as we have seen in the previous section.

Yengoyan (1968a, 1968b, 1970) went even further, adding population density and size of tribes or linguistic groups to the already integrated view of the distribution of social category systems. He suggested complementing the existing correlation between land tenure and social category systems with an additional materialist foundation (see the critique by McKnight 1981), suggesting that types of social organisation are modes of adaptation to different kinds of environment. This additional factor is related to Birdsell's (1953, 1973) theory, for whom the notion of 'equilibrium' between population size, group size and environmental conditions (in particular, mean annual rainfall [Birdsell 1958]) was intrinsic to huntergatherer 'patrilineal-band' societies in general, and Aboriginal Australians in particular. For Birdsell (1973, p. 337), just like Radcliffe-Brown, the patrilineal local group (in contrast to Radcliffe-Brown, Birdsell used the word 'horde') underpins Australian society in general and provides the basis for a possible extension of this Australian model to understand a wider range of hunter-gatherer societies:

The tribe in Australia possesses special attributes which make it particularly suitable and attractive for the investigation of regularities. Australia is the only continent which at the time of contact was exclusively populated by hunting and collecting peoples. These existed in tribal units, totalling 581 in all, a far greater number than anywhere else in the world. The environmental and cultural factors influencing their structure are better known (Birdsell 1953) than for other populations at a similar economic level. They are a model for other cellular-structured patrilinealband types of societies, both those which have persisted elsewhere into present times and those which are presumed to have been preponderant during the Pleistocene. (emphasis added)

Yengoyan (1968b, p. 194) explained that he aimed to explore 'population size ... in terms of its functions and limits on the "ideal" operation of marriage sections', that 'population size is a critical factor in the ideal operation of section systems' (p. 198) and that 'one of the functions of sections and subsections may have been an economic factor in allowing populations to "insure" a vast territorial domain from non-tribal groups' 
(p. 199). Thus, Yengoyan was eager to add the economic and ecological components to Radcliffe-Brown's integrated model. Yengoyan's review of the distribution of social organisation has become tangible evidence, largely in the form of maps, of the encounter between the structuralfunctionalist approach and environmental determinism in Australia.

\section{Mapping Movements and Transformations}

The 1960s and 1970s were decades that announced significant changes in the anthropological discipline and approach to Australian Aboriginal cultures. The functionalist and structuralist-and materialist to a lesser degree-schools that had dominated the landscape until then were increasingly accused of constructing metalanguages based on ethnocentric and dogmatic concepts. The interest in practice gradually replaced the focus on structure and systems (Ortner 1984), and investigations moved away from the comparative (geographical or systemic) to embrace local and culturalist emphases.

This shift also became visible in the cartographic elements that new publications produced. Indeed, continental or even regional maps that had objectives other than only approximately situating a group or community became rare, since the focus had turned to particular cultural or social features and practices or minorities. The Northern Territory Land Rights Act 1976 and National Native Title Act 1993 reinforced this general tendency, even though the involvement of anthropologists in both these processes relied heavily on rather classic anthropological models. They were also accompanied by the waning of interest (or trepidation) in comparative matters and the obvious interpretation of maps as producers of political and legalistic statements. Most, if not all, maps published after 1976, and even more so after 1993, included a footnote or warning indicating that lines were not really borders, shaded areas were not really surfaces, and these maps could not be used for land rights claims, native title claims or any purpose other than a vague illustration. The inherent power of maps had to be neutralised and disengaged, emptied of the very substance that constituted their essence. They were not supposed to produce simplified worlds anymore, quite the opposite; they were to reveal only the surface of complexities that could not be illustrated, placed into space or even described. 
There are of course exceptions to this general trend, such as Berndt and Berndt's (1992 [1964]) and Mulvaney’s (1976) maps, and geographical charts produced by linguists or archaeologists. Interestingly, these exceptions depicted elements of change, diffusion, circulation or exchange, stressing either an inherent dynamic or the necessity of shifting the perspective to depict the fragility of boundaries. With the emphasis on the ethnography of detailed local practices and processes, the consciousness for a far more dynamic, but also more localised, Indigenous world emerged-a world in which social change was not solely a consequence of modernity, but something inherent in Aboriginal culture more generally. How to graphically represent transformation, diffusion and exchange became a new challenge for map-keen anthropologists and researchers.

Berndt and Berndt's 1964 map (1992 [1964], p. 55) is an early and, to some extent, premonitory example, as well as being probably one of the best known and most influential examples (see Figure 8). The spatial distribution of social organisation systems that Berndt and Berndt offer is an enriched and nuanced version of previous maps, such as those of Radcliffe-Brown and Davidson. It does not reconsider or even question the foundation of the definition of social organisation, nor the means through which these types contribute to fabricating implicit similarities or differences of Aboriginal life-ways. If we consider the expansion of the section system alone (see Figure 9), we can indeed see that the difference of scope between Radcliffe-Brown's and Berndt and Berndt's maps, and even Mathews's map, is not largely significant.

However, Berndt and Berndt's (1992 [1964]) map (Figure 8) incorporates some considerable differences from previous ones, producing a new kind of aesthetic. There is no drive to fully cover the continent or entire regions with areas particular to specific types of social organisation. Completeness is not necessarily the central ambition. There are empty spaces between rough and suggestive lines and curves, testifying to the confession of a lack of information and acknowledgement of sometimes-fuzzy distinctions and overlaps between typological areas. 


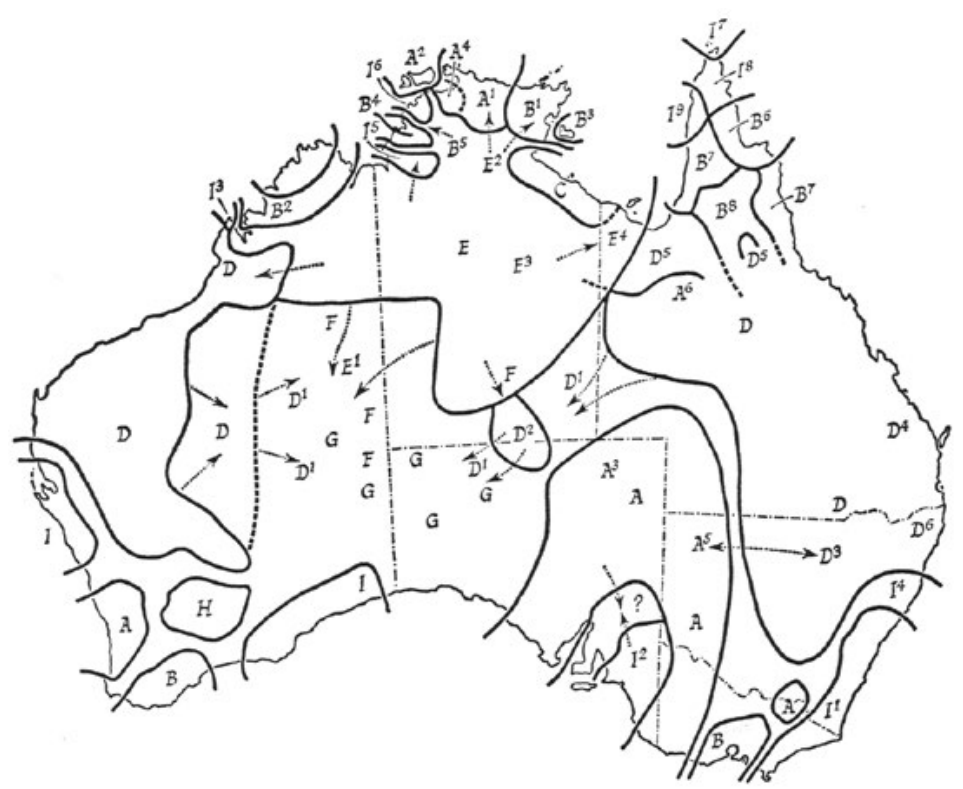

Figure 8: Berndt and Berndt's map of the distribution and spread of social organisations.

Source: Berndt and Berndt (1992 [1964], p. 55), reproduced with permission from HarperCollins.

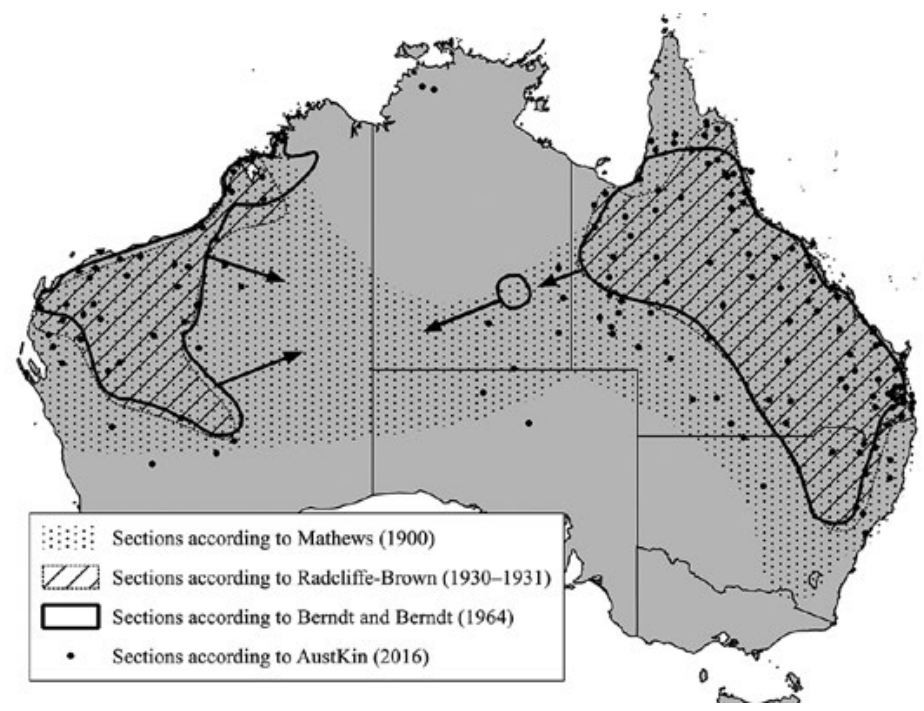

Figure 9: An approximate extension of the four-section system according to Mathews, Radcliffe-Brown, Berndt and Berndt and AustKin.

Source: Compilation by L. Dousset from sources mentioned on map legend. 
Berndt and Berndt's (1992 [1964]) map is also distinctive for its addition of more types and subtypes than previous maps had included. The accumulation of knowledge on precise local systems and terminologies, and the identification of a far greater systemic diversity than had emerged from the new anthropological practice are reproduced in Berndt and Berndt's (1992 [1964]) typology and its geographic placement. Most importantly, the map now contained many arrows that crisscross typological areas and is captioned 'Distributional spread of Australian Aboriginal social organisation', rightly pointing to an inherent feature of social organisation. Herein lies the most significant change from any of the other previously discussed approaches and maps. It is often difficult, and in many cases arbitrary to some extent, to identify which areas are characteristic of any system of social organisation; further, the movement, overlap, extension and retraction of such systems in space and time become one of the main characteristics and scientific messages that are produced in this map, as well as others. Maps now reflect the cognition of a world of which the grasp from a static bird's-eye view is becoming increasingly difficult.

Although this chapter principally deals with anthropologists, the maps of archaeologist Derek John Mulvaney (see Figure 10) are an excellent example of this renewed articulation of mapping of Indigenous realities. The presence of identified specific sites and arrows of possible circulation of people, knowledge and particular practices, and absence of tribal or linguistic names and borders or shaded areas, are the core features of a geographical representation that is disengaged from the former typological approaches. 


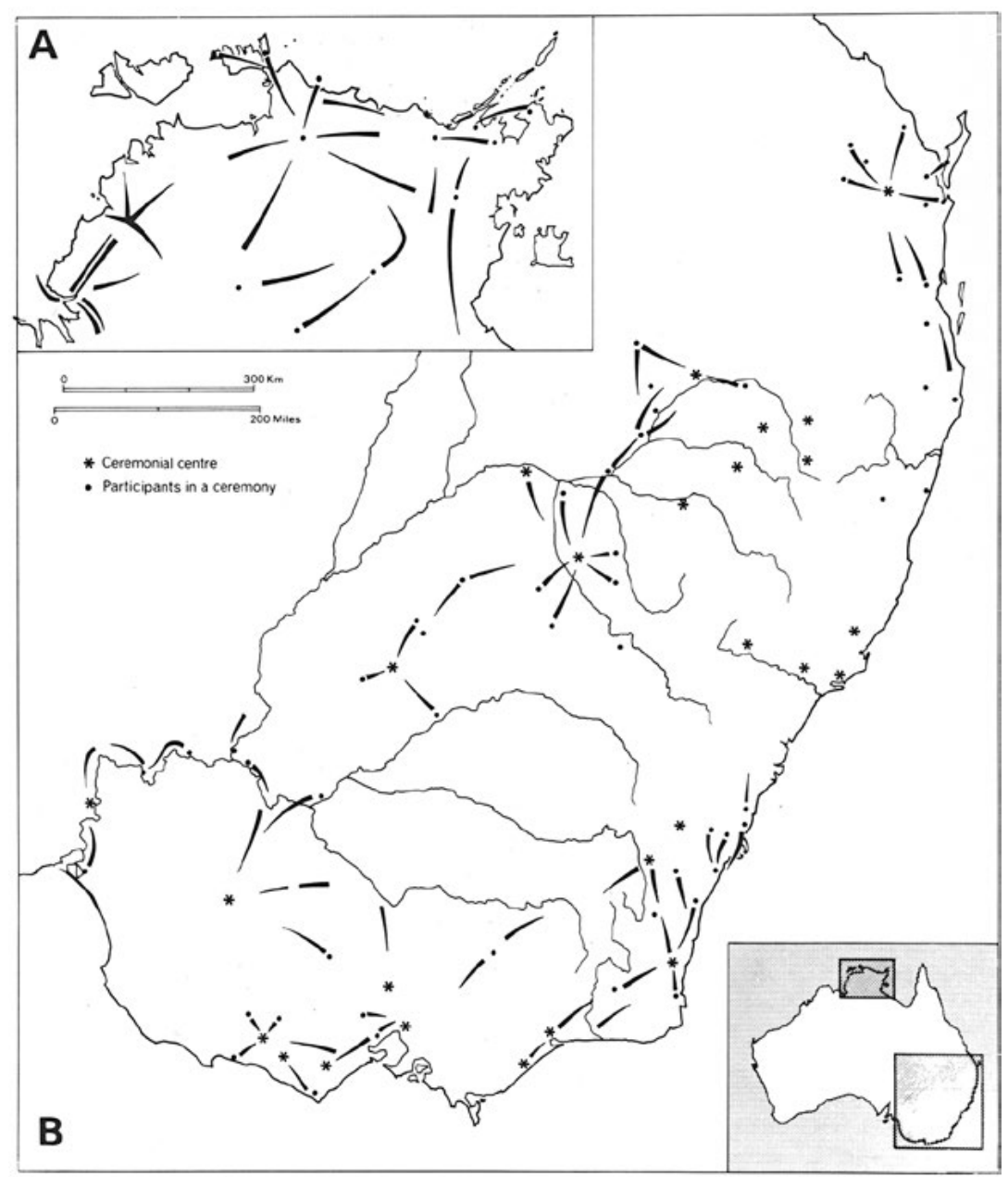

Figure 10: One of Mulvaney's maps showing ceremonial exchange, ceremonial centres and home localities of ceremonial participants.

Source: Mulvaney (1976, p. 76).

Interestingly, Mulvaney's and Nicolas Peterson's chapters, which both reflect this new approach to Aboriginal space, are published in the same volume (Peterson 1976b), alongside contributions by Tindale and Birdsell, even though the latter two are representative figures of the former generation of map-making researchers. In a similar way to Mulvaney, Peterson (1976a) proposed culture areas based on drainage divisions (see Figure 11), and suggested the investigation of affinities, similarities and differences articulated around grand structural features of the landscape 
rather than cultural typologies. He also acknowledged the existence of movement, exchange and communication between Indigenous groups that increases the complexity of marking cultural or tribal boundaries, as the following explanation testifies:

The realities of these culture-areas circumscribing populations is open to some independent checking and validation. If the natural boundaries have an historical consequence in tending to restrict communication between the culture-areas, the culture-areas will tend to be endogamous. (Peterson 1976a, p. 67)

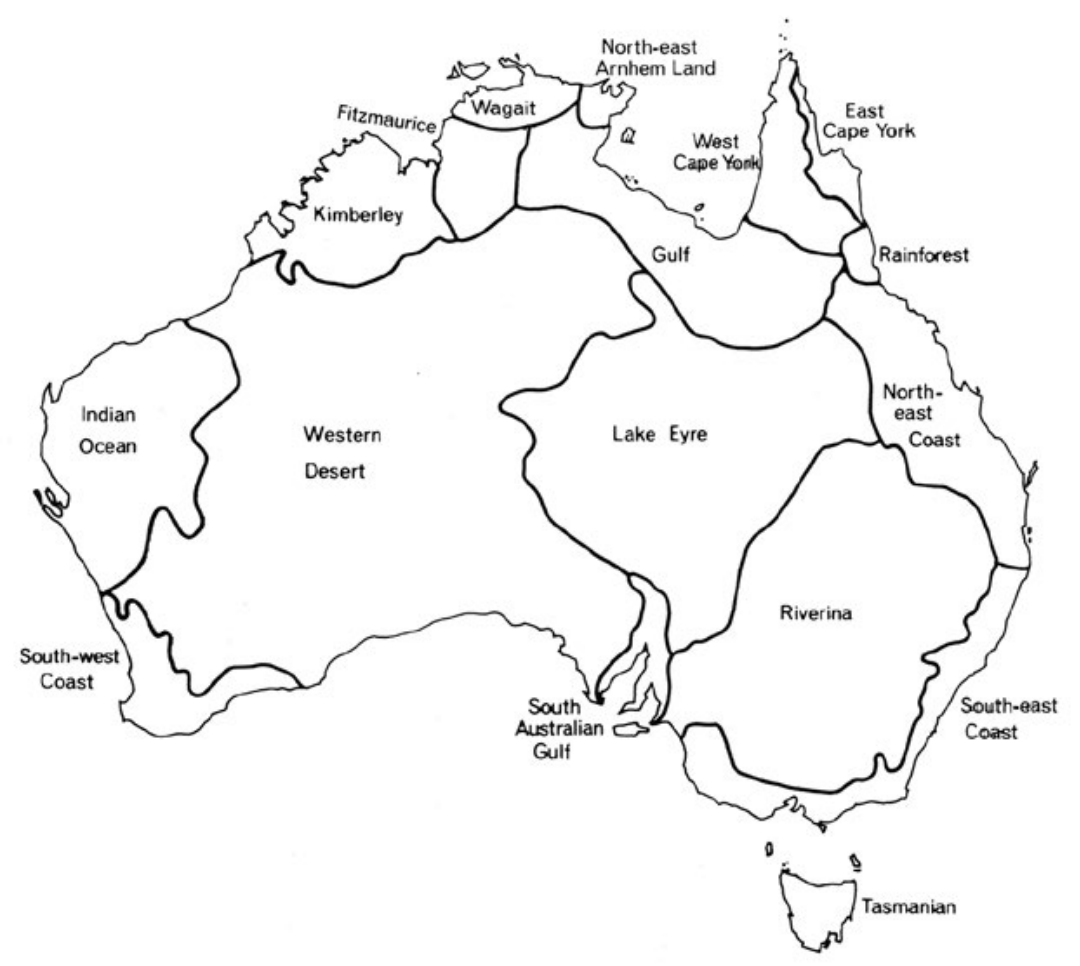

Figure 11: Peterson's drainage basins.

Source: Peterson (1976a).

These maps also reflect a change in the understanding of social organisation and its use in comparative or historical approaches. While in previous periods, terminology and system types in particular were seen as characteristics that could be deployed to compare and map Australian cultures more generally, and were understood as strong indicators of historical or social similarities and differences, they are now one of many 
other elements that contribute to the analysis of social and cultural dynamics-past and present. In this general trend, maps have again become central and explanatory devices-for example, those produced by linguists such as McConvell (1985a, 1985b) or Dousset (2005), both representing possible routes of diffusion of sections or subsections. Freed from being political statements, these maps do not imply boundaries, tribal areas or cultural blocs as such, and they do not reconstruct historical or evolutionary stages that reflect continental-wide schemes. However, they tackle precise and historically situated ethnographic and linguistic data that, represented in space, provide an overview not of Aboriginal culture or general typologies, but of the historical and social dynamics that become visible through the study of social organisation.

\section{Mapping within the AustKin Project}

These preliminary conclusions underpin the general framework of the AustKin project, in which many contributors to this volume participated. The general scope-using digital means such as databases, programming and graphical information systems (GIS) — was to elaborate an account as precise as possible of the spatial and temporal distribution of kinship terminologies in the first phase, and of elements of social organisation in the second phase of the project. In this short account of AustKin, I predominantly reflect on the methodologies adopted during the second phase-that is, the study of social organisation. The project is particularly, but not exclusively, interested in the Indigenous terminologies and relationships that these terms express in terms of kin relationships, as well as the possible changes that these terms and relationships underwent in time and space. To avoid, or at least confront the problems of the past, we had to reflect on the precepts to be adopted in three particular domains: nature of information, digital coding of linguistic and systemic characteristics, and means and meanings of spatial representation. While I can only provide a very succinct overview of the thoughts that guided our work, I consider these to have been necessary steps in the course of adopting a critical perspective with regard to the content and nature of mapping. 


\section{The Nature of Information}

The database system we constructed was made to incorporate data as an 'archival testimony' of something observed (or thought to have been observed) at any particular place and time-not to reflect on whether information was accurate or inaccurate, or true or not. To illustrate with a general example, the expression 'such and such group has a section system with the following terms' is not something we would take for granted. Instead, the database system would record this information in the following terms: 'a group identified as such and such by such and such author, recorded at such and such place and year, is reported to be using the following terms in what is likely to be such and such system type'. Thus, every ethnographic report is treated as a non-exclusive historical record to be included or omitted in any particular context or question that makes use of the data. Moreover, every record is linked to an estimated linguistic entity (based on the official AIATSIS [2017] language list), author, time period and, if possible, geographic place of recording, as well as the reference from which the information was obtained.

Social category terminologies and relationships are interpreted as a historical record of Indigenous cultures, but they are always considered to have been produced in a particular context. This approach allows the integration of several versions of what is supposed to be identical information, such as when more than one researcher works in the same area. Additionally, it provides an opportunity for crosschecking and selective processing of the information that is to be mapped. Further, recording information from various sources on the same language group opens up the possibility of analysis of change over time-whether this change is due to shifting methodologies and scientific backgrounds, or actual sociohistorical and linguistic shifts.

\section{The Digital Coding of Systemic Characteristics}

Another important aspect was to code the information in a useful way (allowing for diachronic and comparative analysis), while remaining as neutral as possible. Ridington (1969, pp. 460-1) suggested reading Beaver Indian's kinship system as a two-section system without sections-that is, 'a system with two egocentric conceptual marriage categories that have not crystalized into a sociocentric moiety system because of ecological conditions that favour flexibility in marriage and group affiliation'. This kind of system is probably better termed a 'covert moiety' system, rather 
than a section system. In particular, it poses the unresolved question of whether covered (not spelled out) systems or categories should be taken into account in descriptions and analysis.

In light of the necessity to formally code data in the AustKin system, the notion of covert characteristics has eventually been adopted as the most neutral and efficient means to representing social category systems. While I am still not convinced that a 'mathematical' or 'formal' feature that has no emic counterpart should be accounted for in an anthropological analysis, the process of decomposing systems of social organisation into covered components enables the elaboration of a model that allows for internal (within the terminological system) and external (between different system types) assessments. Once the existence of covert or logical components is accepted, the various system types can indeed be described in terms of each other.

Let me illustrate this statement through the examination of the section system. It can be read as being built around the combination of a covert (unnamed) or overt (named) matrimoiety system with a covert or overt patrimoiety system. Note here that I use 'moieties' to illustrate sections for the sake of explaining the coding of data only, with no implications on whether these moieties actually exist in a particular language or not. Here, they are a mathematical property of a section system. Each person belongs to one of the four sections, and simultaneously to one of the two patrimoieties and to one of the two matrimoieties. Marriage must take place with someone of the other patrimoiety and of the other matrimoiety of oneself, thus resulting in a section system.

Figure 12 represents the four sections, with each being the combination of a matrimoiety (letters) and a patrimoiety (numbers): A1, A2, B1 and B2. A and B are the two (covered) matrimoieties; 1 and 2 are the two (covered) patrimoieties. Each person is the combination of his or her double moiety affiliation, so that a person in A1 inherits A from his or her mother (matrifiliation) and 1 from his or her father (patrifiliation). As there is an obligation of exogamy from each moiety system, A1 must marry someone from $B$ and someone from 2 , and thus find a spouse in B2. A1 is the child of a woman A2 because he or she inherits A from the mother and 1 from the father. A1 and $\mathrm{B} 2$ of the same generational level are cross-cousins to each other. The same is true for $\mathrm{A} 2$ and $\mathrm{B} 1$. 


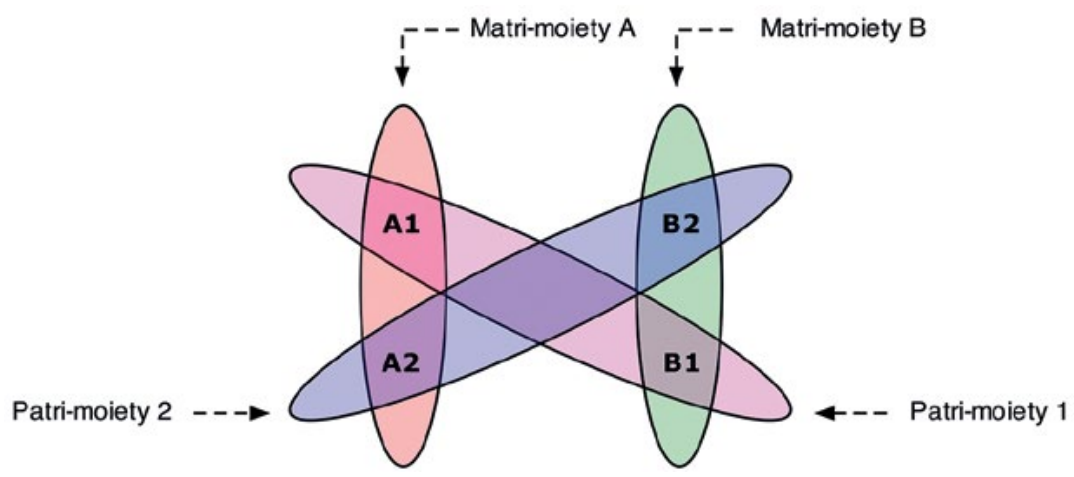

Figure 12: Formal representation of the section system.

(Compare this with the section system of Figure 4.)

Source: Adapted from Dousset (2011, p. 108).

The same principles (using different positions and additional components) can obviously be used to describe patrimoiety and matrimoiety systems, as well as generational moieties, semi-moieties or subsections, resulting in a four-character string that is applicable to all positions in all systems without implying any preliminary and biased interpretation (see Table 3). ${ }^{12}$

Table 3: Coding systems for social categories.

\begin{tabular}{|l|l|c|c|c|}
\hline Place in code & Meaning & $\begin{array}{c}\text { If irrelevant } \\
\text { to describe } \\
\text { the system }\end{array}$ & \multicolumn{2}{|c|}{$\begin{array}{c}\text { If relevant, one } \\
\text { of the following } \\
\text { values is possible }\end{array}$} \\
\hline First position & Gender & 0 & $\mathrm{M}$ & $\mathrm{F}$ \\
\hline Second position & Generation & 0 & $\mathrm{G}$ & $\mathrm{H}$ \\
\hline Third position & Matrifiliation/matrimoiety & 0 & $\mathrm{~A}$ & $\mathrm{~B}$ \\
\hline Fourth position & Patrifiliation/patrimoiety & 0 & 1 or 3 & 2 or 4 \\
\hline
\end{tabular}

Source: Author's work.

The 'translation' of the Indigenous terms for each position in their respective systems is coded in Table 4.

12 My acknowledgement goes to Tom Honeyman, The Australian National University, who has contributed substantially to the development of this coding. 
Table 4: Examples of social category coding.

\begin{tabular}{|l|c|l|l|l|l|l|l|l|}
\hline System type & \multicolumn{7}{|c|}{ Possible positions } \\
\hline Matrimoieties & O0A0 & O0B0 & & & & & & \\
\hline Patrimoieties & 0001 & 0002 & & & & & & \\
\hline $\begin{array}{l}\text { Generational } \\
\text { moieties }\end{array}$ & $0 G 00$ & OH00 & & & & & & \\
\hline Sections & O0A1 & OOB2 & OOA2 & 00B1 & & & & \\
\hline Subsections & OGA1 & OGB2 & OGA2 & OGB1 & OHA3 & OHB4 & OHA4 & OHB3 \\
\hline $\begin{array}{l}\text { Subsections } \\
\text { gendered) }\end{array}$ & MGA1 & FGB2 & FGA1 & MGB2 & MGA2 & FGB1 & FGA2 & etc. \\
\hline
\end{tabular}

Source: Author's work.

The advantages of this coding are considerable. First, the minimal but necessary amount of information needed to describe a system or terminology is palpable. Second, this coding does not imply significant biases or interpretative constructions, while retaining its capacity for identification and comparison. Third, it is possible to make an informed guess about the type of system encountered even when the terminology reported by the observer is incomplete. Finally, comparative and diachronic analysis of terminologies of identical or multiple system types, as well as terminological permutations, can proceed by comparing the values observed for each component.

\section{The Means and Meaning of Spatial Representation}

Despite the previously mentioned precautions, mapping of information remains a complex process, with the selection of accurate coordinates being a key component. Figure 3 perfectly illustrates the difficulties. This map represents several system types recorded by observers at any time of the archival history documented in the AustKin database. For reasons already discussed, these system types have been placed in space as symbols, without inferring any borders, and allowing for the coexistence of several types within one and the same area or language. The coordinates used for each of these languages have been critically constructed by comparing various sources ${ }^{13}$ and are believed to be reasonably accurate-at least for the purpose of mapping social organisation. However, Figure 3 also infers that any particular language or group located today was at the same location in 1834, which is the oldest archival source recorded in AustKin

13 These sources are Tindale's (1974) maps, the AIATSIS (2017) online mapping system known as AUSTLANG and other local sources used to adjust particular coordinates. 
thus far. Essentially, while it is conceivable to map movements of system types in space, and theoretically possible to map movements of languages in space, it is highly difficult to display, on a continental scope, both these movements at the same time. Moreover, it is also very difficult to evaluate if the 'absence' of a system at a time in history and the 'presence' of the same system decades later is a historical change or simply the result of an early incomplete observation.

Figure 13 is another illustration of these complexities. As can be seen, the areas reflecting the distribution of section systems reported before 1930 and the distribution of the systems reported from 1930 onwards do not overlap in large areas. Explanations can be provided for some of these discrepancies. For example, two reasons are given for why section systems are only reported for the periphery of the Western Desert in Western Australia before 1930. First, the bulk of fieldwork in this area only started after the 1930s, and for some areas only after the 1950s. Thus, the information was simply not available earlier. Second, we also know that many groups only recently adopted the section system in this area (Dousset 2005), and after 1930 for the interior regions.

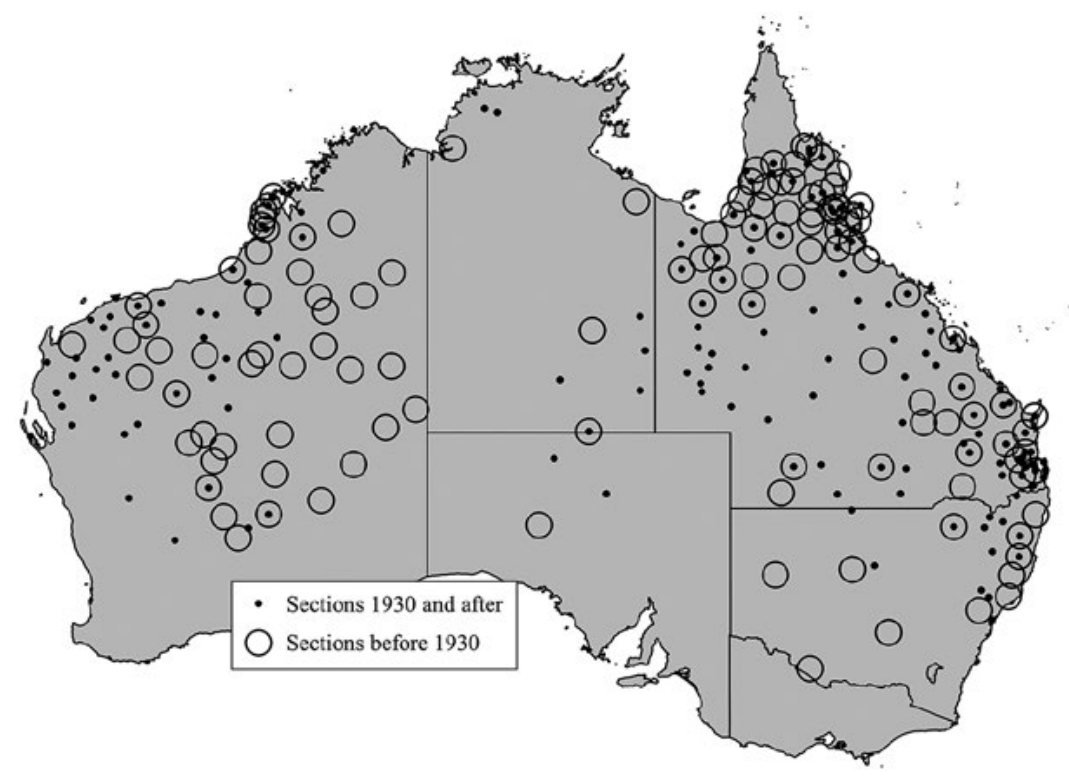

Figure 13: Map generated from the AustKin database of the distribution of section systems.

Small dark circles represent the section systems reported before 1930; large transparent circles represent the section systems reported from 1930 onwards.

Source: Prepared by L. Dousset from various sources. 
Explaining the many discrepancies in general terms remains a difficult task. Are the discrepancies due to moving groups, groups adopting new systems (e.g. subsection system) and dropping other systems (e.g. section system), incomplete ethnographies or lack of interest in matters of social organisation, or the diffusion of social category systems? In many cases, the answers to these questions cannot be obtained unless a possible history is reconstructed for each particular location.

\section{Conclusion}

This chapter has attempted to outline some general trends that emerged during the evolution of anthropological maps on Aboriginal Australia in the twentieth century. These trends reflect specific but changing conceptions of society in general, and of Aboriginal culture in particular. Due to their inherent capacity to reproduce simplified and transportable worlds, it is not surprising that maps tend to crystallise the most fundamental aspect of the scientific message of the author. Maps are thus the result of particular and necessary partial epistemological approaches. Cartographic representations are built around the feature of certain traces and the oblivion of others. Lines, shades, areas, arrows, colours, points and icons fabricate a visibility that emerges from all that remains invisible. They are interpretative grids, potentially detached from their real-world background of emergence.

The evolution of mapping Aboriginal Australia and social organisation in particular in the anthropological discipline during the twentieth century reflects a departure from the generalist and homogenising attitudes of the former evolutionist approach. Indeed, the evolutionist approach is characterised by rather superficial and incomplete ethnographic data, and for its immense ambitions for continental-wide reconstructions. Social organisation has in this context served as a tool for comparison of culture and society, and is understood as a central and distinctive feature of Australian Aboriginal society.

The structural-functionalist approach that progressively replaced earlier evolutionary speculations from the first decades of the twentieth century onwards changed the scope of the anthropological enterprise-and with it, the nature of mapping. Local cultures and systems were at the centre of investigation, with a considerable increase in the quality and quantity of data. However, the approach remains a holistic one: the social system as 
a whole had to make sense, and its elements or features had to be mutually tuned and adapted. The necessity for typologies emerged from this second imperative, and it is these typologies - constructing an integrated view of social organisation, land tenure and other social features-that became the central object of mapping.

From the 1960s and 1970s onwards, with the decline of anthropological metadiscourses and the emergence of culturalist and relativist approaches, maps progressively disappeared from publications for at least two reasons: the consciousness of the potential political and legalistic messages conveyed by maps, and a deflection from comparative studies. Thus, researchers that retained regional and continental or historical interests started to produce new forms of maps in which social dynamics, rather than cultural or social areas, became the object of representation. This coincided with the theoretical and ethnographical reconsiderations of the critique on conjectural history that is one of the trademarks of the structural-functionalist school. Provided societies are not considered discrete and integrated systems, linguistic and ethnographic elements may be considered testimonies or indicators of social change, exchange and diffusion. Aboriginal society, in this context, was increasingly seen as inherently dynamic, and maps turned away from featuring borders and instead displayed arrows and shading.

This renewed approach to cultural geography that integrates dynamic and historical spaces is confronted with new technical and epistemological problems: maps now need to be both spatial and chronological, while retaining their portability, power for simplification and explanation, and capacity for replication in new frameworks of knowledge production. These are some of the challenges that we have attempted to address in the AustKin project.

\section{References}

AustKin 2017, The AustKin project, viewed 31 July 2017, www.austkin.net.

Australian Institute of Aboriginal and Torres Strait Islander Studies (AIATSIS) 2017, Welcome to AUSTLANG, viewed 31 July 2017, austlang.aiatsis.gov.au. 
Berndt, RM \& Berndt, CH 1992 [1964], The world of the First Australians. Aboriginal traditional life: past and present, London: Angus $\&$ Robertson.

Birdsell, JB 1953, 'Some environmental and cultural factors influencing the structuring of Australian Aboriginal Populations', The American Naturalist, 87(834), pp. 171-207. doi.org/10.1086/281776.

Birdsell, JB 1958, 'On population structure in generalized hunting and collecting populations', Evolution, 12(2), pp. 189-205. doi.org/ 10.1111/j.1558-5646.1958.tb02945.x.

Birdsell, JB 1973, 'A basic demographic unit', Current Anthropology, 14(4), pp. 337-56. doi.org/10.1086/201347.

Blackburn, K 2002, 'Mapping Aboriginal nations: the "nation" concept of late nineteenth century anthropologist in Australia', Aboriginal History, 26, pp. 131-58.

Connelly, JF 1932, 'Distribution of tribes in Western Australia', Mankind, 1(5), p. 101.

Cooper, E 1983, 'Ten-section systems, Omaha kinship, and dispersed alliance among the ancient Chinese', Current Anthropology, 24(3), pp. 327-40. doi.org/10.1086/203002.

D’Andrade, RG 1992, 'Cognitive anthropology', in T Schwartz, GM White \& CA Lutz (eds), New directions in psychological anthropology, Cambridge: Cambridge University Press, pp. 47-58.

Davidson, DS 1926, 'The basis of social organization in Australia', American Anthropologist, 28(3), pp. 529-48. doi.org/10.1525/aa. 1926.28.3.02a00040.

Davidson, DS 1928, The chronological aspects of certain Australian social institutions as inferred from geographical distribution, Philadelphia: University of Pennsylvania Press.

Davidson, DS 1936, 'Spearthrower in Australia', Proceedings of the American Philosophical Society, 76(4), pp. 445-83.

Davidson, DS 1938, 'An ethnic map of Australia', Proceedings of the American Philosophical Society, 79(4), pp. 649-79. 
Davis, SL 1993, Australia's extant and imputed traditional Aboriginal territories (map), Melbourne: Melbourne University Press.

de Foigny, Gabriel 1990 [1676], La terre Australie connue, Paris: S.T.F.M. $\&$ Aux Amateurs de Livres.

Demerath III, NJ 1966, 'Synecdoche and structural-functionalism', Social Force, 44(3), pp. 390-401. doi.org/10.1093/sf/44.3.390.

Dousset, L 2005, Assimilating identities: social networks and the diffusion of sections, Sydney: Oceania Publications, Monograph 57.

Dousset, L 2011, Australian Aboriginal kinship: an introductory handbook with particular emphasis on the Western Desert, Marseille: Pacific-Credo Publications.

Dousset, L \& Glaskin, K 2007, 'Western Desert and native title: how models become myths', Anthropological Forum, 17(2): pp. 127-48. doi.org/10.1080/00664670701438399.

Elkin, AP 1974 [1938], The Australian Aborigines, revised edition, London, Sydney: Angus \& Robertson Publishers.

Estensen, M 1998, Discovery: The quest for the great south land, St Leonards, NSW: Allen \& Unwin.

Etherington, N (ed.) 2007, Mapping colonial conquest: Australia and southern Africa, Crawley, WA: University of Western Australia Press.

Fry, HK 1933, 'Australian marriage rules', Sociological Review, 22, pp. 258-77. doi.org/10.1111/j.1467-954X.1933.tb01884.x.

Glaskin, K \& Dousset, L 2011, 'Asymmetry of recognition: law, society and customary land tenure in Australia', Pacific Studies, 34(2-3), pp. 142-56.

Goddard, C 1992 [1987], Pitjantjatjara/Yankunytjatjara to English dictionary, Alice Springs: Institute for Aboriginal Development.

Graebner, F 1906, 'Wanderung und Entwicklung sozialer systeme in Australien', Globus, XC, pp. 181-6, 207-10, 220-4, 237-41.

Harley, JB 1991, 'The new history of cartography', UNESCO Courier, June 1991. 
Hornborg, A 1993, 'Panoan marriage sections: a comparative perspective', Ethnology, 32(1), pp. 101-8.

Horton, D 1996, Aboriginal Australia (map), Canberra: AIATSIS, AUSLIG.

Howitt, AW 1883, 'Notes on the Australian class systems', The Journal of the Anthropological Institute of Great Britain and Ireland, 12, pp. 496-512. doi.org/10.2307/2841688.

Howitt, AW 1996 [1904], The native tribes of south-east Australia, Canberra, London: Aboriginal Studies Press, Macmillan \& Co.

Howitt, AW \& Fison, L 1885, 'On the deme and the horde', Journal of the Anthropological Institute, 14, pp. 142-68. doi.org/10.2307/2841853.

Keen, I 2000, 'The anthropologist as geologist: Howitt in colonial Gippsland (review article)', The Australian Journal of Anthropology, 11(1), pp. 78-97. doi.org/10.1111/j.1835-9310.2000.tb00264.x.

Kryukov, M 2004, From ancient Chinese to contemporary mnong-gar, Unpublished manuscript.

Lane, RB \& Lane, BS 1956, 'A reinterpretation of the "anomalous" six-section marriage system of Ambrym, New Hebrides', Southwestern Journal of Anthropology, 12, pp. 406-14. doi.org/10.1086/soutjanth. 12.4.3629065.

Latour, B 1987, Science in action: how to follow scientists and engineers through society, Cambridge: Harvard University Press.

Le Testu, G 1556, Cosmographie universelle selon les navigateurs tant anciens que modernes, Le Havre.

Lestringant, F 2013, 'La cosmographie universelle de Guillaume Le Test (1556)', CFC, 216, pp. 91-107.

Lévi-Strauss, C 1967 [1947], Les structures élémentaires de la parenté, Paris: Mouton.

Lévi-Strauss, C 1996 [1973], Anthropologie Structurale II, Paris: Plon.

Maddock, K 1972, The Australian Aborigines: a portrait of their society, Ringwood, Victoria: Penguin Books. 
Mathews, RH 1900, 'The origins, organisation and ceremonies of the Australian Aborigines', Proceedings of the American Philosophical Society, Philadelphia, 39(164), pp. 556-78.

McConvell, P 1985a, 'The origin of subsections in northern Australia', Oceania, 56(1), pp. 1-33. doi.org/10.1002/j.1834-4461.1985.tb 02105.x.

McConvell, P 1985b, 'Time perspective in Aboriginal Australian culture: two approaches to the origin of subsections', Aboriginal History, 9(1), pp. 53-80.

McConvell, P 1996, 'Backtracking to Babel: the chronology of PamaNyungan expansion in Australia', Archaeology in Oceania, 31(3), pp. 125-44. doi.org/10.1002/j.1834-4453.1996.tb00356.x.

McConvell, P 2013, “Universal kinship" and "sociocentric kin categories": ancient and human traits?', Australian Anthropological Society Annual Conference, November 2013, Canberra: The Australian National University.

McKnight, D 1981, Distribution of Australian Aboriginal 'marriage classes': environmental and demographic influences, $\operatorname{Man}$ (n.s.), 16(1), pp. 75-89.

McLennan, JF 1970 [1865], Primitive marriage: an inquiry into the origin of the form of capture in marriage ceremonies, Chicago: University of Chicago Press.

Mulvaney, DJ 1976, “The chain of connection”: the material evidence', in N Peterson (ed.), Tribes and boundaries in Australia, Canberra: Australian Institute of Aboriginal Studies, pp. 72-94.

Ortner, S 1984, 'Theory in anthropology since the sixties', Comparative Studies in Society and History, 26(1), pp. 126-66. doi.org/10.1017/ S0010417500010811.

Patterson, M 1976, Kinship, marriage and ritual in North Ambrym, PhD thesis, University of Sydney.

Peterson, N 1976a. 'The natural and cultural areas of Aboriginal Australia', in N Peterson (ed.), Tribes and boundaries in Australia, Canberra: Australian Institute of Aboriginal Studies, Social Anthropology Series no. 10 , pp. $50-71$. 
Peterson, N (ed.) 1976b, Tribes and boundaries in Australia, Canberra: Australian Institute of Aboriginal Studies, Social Anthropology Series no. 10.

Radcliffe-Brown, AR 1913, 'Three tribes of Western Australia', Journal of the Royal Anthropological Institute of Great Britain and Ireland, 43, pp. 143-94. doi.org/10.2307/2843166.

Radcliffe-Brown, AR 1930, 'Former numbers and distribution of Australian Aborigines', Official Yearbook of the Commonwealth of Australia, 23, pp. 671-96.

Radcliffe-Brown, AR 1941, 'The study of kinship systems', Journal of the Royal Anthropological Institute, 71(1-2), pp. 1-18. doi.org/ $10.2307 / 2844398$.

Ricoeur, P 2000, La mémoire, l'histoire, l'oubli, Paris: Seuil.

Ridington, R 1969, 'Kin categories versus kin groups: a two-section system without sections', Ethnology, 8(4), pp. 460-7. doi.org/ $10.2307 / 3772911$.

Schmidt, W 1912, 'Die gliederung der Australischen sprachen', Anthropos, 7(1), pp. 230-51.

Schmidt, W 1919, Die gliederung der Australischen Sprachen: geographische, bibliographische, linguistische Grundzüge der Erforschung der Australischen sprachen, Wien: Mechitharisten-Buchdrückerei.

Shapiro, W 1969, 'Semi-moiety organisation and mother-in-law bestowal in northeast Arnhem Land', Man (n.s), 4(4), pp. 629-40.

Sutton, P 1995, Country: Aboriginal boundaries and land ownership in Australia, Canberra: Aboriginal History Monograph 3.

Sutton, P 1998a, 'Aboriginal maps and plans', in D Woodward \& GM Lewis (eds), The history of cartography: cartography in the traditional African, American, Arctic, Australian, and Pacific societies, vol. 2, book 3, Chicago and London: University of Chicago Press, pp. 387-416. 
Sutton, P 1998b, 'Icons of country: topographic representations in classical Aboriginal traditions', in D Woodward \& GM Lewis (eds), The history of cartography: cartography in the traditional African, American, Arctic, Australian, and Pacific societies, vol. 2, book 3, Chicago and London: University of Chicago Press, pp. 353-86.

Tindale, NB 1974, Aboriginal tribes of Australia, Berkeley: University of California Press.

Wikipedia 2012, File: Ortelius_Maris Pacifici 1589.jpg, en.wikipedia. org/wiki/File:Ortelius_-_Maris_Pacifici_1589.jpg, accessed 3 February 2014.

Yengoyan, AA 1968a, 'Australian section systems-demographic components and interactional similarities with the !Kung bushmen', Proceedings of the VIII International Congress of Anthropological and Ethnological Sciences, 3, pp. 256-60.

Yengoyan, AA 1968b, 'Demographic and ecological influences on Aboriginal Australian marriage sections', in RB Lee \& I De Vore (eds), Man the Hunter, Chicago: Aldine, pp. 185-190.

Yengoyan, AA 1970, 'Demographic factors in Pitjandjara social organisation', in RM Berndt (ed.), Australian Aboriginal Anthropology, Canberra: Australian Institute of Aboriginal Studies, pp. 70-91.

Young, E 1995, 'Aboriginal frontiers and boundaries', in P Sutton, Country: Aboriginal boundaries and land ownership in Australia, Canberra: Aboriginal History Monograph 3, pp. 88-92. 
This text is taken from Skin, Kin and Clan: The dynamics of social categories in Indigenous Australia, edited by Patrick McConvell, Piers Kelly and Sébastien Lacrampe, published 2018 by ANU Press, The Australian National University, Canberra, Australia.

doi.org/10.22459/SKC.04.2018.03 